\title{
INTERVIEW
}

\section{Investigating Desires, Political Projects and Epistemic Habits in Academic Feminism: A Conversation with Robyn Wiegman}

\author{
Robyn Wiegman ${ }^{1 *}$, Salla Peltonen ${ }^{2}$
}

Published: October 30, 2017

\begin{abstract}
The interview discusses the stakes in current debates regarding critique and addresses the challenges and the impasses that characterise our political present. The interview also explores questions concerning queer method, critical reading practices and the desires and political projects that have motivated feminist academic work.
\end{abstract}

Keywords: critique, epistemic habits, queer theory, method, postcritique

\section{THE INTERVIEW}

Salla: How do you see and understand the current discussions on critique within the field of gender studies and queer theory?

Robyn: It's not always easy to separate the conversation about critique in gender studies and queer theory from the larger academic conversation in which the 'critique of critique' currently circulates. This larger conversation tends to emphasise the value of the humanities and its orientation toward the study of culture in ways that don't fully jive with the field's distinctly left political intentions. For scholars like Rita Felski, the humanities undercuts itself by not being able to forge a positive relationship to its various objects of study, with the literary being at the heart of her concerns. Her suspicion of suspicious reading arises, in part, because of the way the critic's relationship to the literary object has been coded as naïve if it aligns more with love, affection, or desire than with reprimand, intervention, or disagreement. In this concern for the affects that shape criticism, Felski's argument sounds a lot like Eve Kosofsky Sedgwick's early take on paranoid reading but the contexts that prompted them are quite different. Sedgwick was writing against the paranoia that AIDS had unleashed in order to make space for work that could nurture and repair broken worlds. While she thought that the suspicious mode engendered highly predictable criticism, she was not out to defend the literary object nor did she think that critique was exhausted or self-defeating. She wanted other methodological and affective options for the political work of antihomophobic criticism. Many of the endeavors that have emerged to counter critique are staked to an ethics of reading more so than the political commitments of left criticism. Both are valuable but they are not the same project.

Salla: These endeavours go by various names: surface reading, slow reading, distance reading, weak description. Do you favour one over the other, or do you find the arguments in defence of critique to be most convincing, especially for the work we do in women's, gender and queer studies?

Robyn: In some ways, I find the very proliferation of options to be more interesting than the options themselves, though if pressed I guess I would want to forge my own synthesis, something that emphasises description - but I don't want it to be weak - and slowness, given that both of these require careful reading and a certain suspension of the critic's authority. At the same time, as you might guess, I'm attracted to scholars who resist the lure to proclaim 'the new', especially Elizabeth Weed and Ellen Rooney, both of whom defend the political value of critique by giving us a different account of the history and critical force of symptomatic reading. 
Their counter-arguments illuminate the way the debate has covertly pitted theory against literature and ascribed too much agency to theory in the decline of the humanities in the last forty years. Nevertheless, I think it is a problem to cast the debate in strictly oppositional terms, as if one must be 'for' or 'against' critique, 'for' or 'against' surface reading. What interests me the most right now is how best to understand why critique has become the central figure in debates about critical practice and academic authority: what is being sought? What gets displaced? What are the fault lines in these conversations?

\section{Salla: So you're suspicious about the suspicion over critique?}

Robyn: I guess so! But only to the extent that I think there's something to learn about why the debate has emerged now and what its implications are for the work of gender and queer studies - or any left academic project for that matter. That's why I'm less interested in pledging allegiance to one of the many projects that take aim at critique on behalf of literary objects and the institutional status of the humanities than I am in cultivating resources to understand the relationship between critique and the conditions of our political present. In Object Lessons, I was trying to parse the utility and limit of critique for identity knowledges as a whole, but not in the name of a new mode of criticism. My main concern was the insatiability of the political desire that underwrote scholarship in gender, women, queer, ethnic, and American Studies, and what it means when a field begins to view the objects, concepts, or methods that once defined it as the source of political betrayal. I would go further today and talk about the aggression that gets masked in identity knowledges by our various attempts to find objects we not only can love but love unambivalently, and how the disavowal of aggression is sustained through a highly moralised discourse of political radicality.

Salla: And what about the relationship between critique and the political present? Some critics argue that it is best to describe our current moment as 'post critique'.

Robyn: The concept of 'post-critique' seems to mean different things to different people. For some, it marks the decline of critique's allure in favour of other critical modes, typically those that choose love over suspicion, as I've mentioned, or hope and optimism over negativity. For others - and I would count myself here - it describes the political impasse of the present. In her recently published book Neocitizenship: Political Culture after Democracy, Eva Cherniavsky argues compellingly that the conditions in which critique had political traction have largely disappeared under neoliberalism, as the tenuous compact between the nation and the state has fractured, corporations have become persons, and the citizen has been refashioned as a self-maximising entity whose consent to be governed is no longer cultivated by those in power. For Cherniavsky, this is because the neoliberal state is not a hegemonic formation in the Gramscian sense. The Trump administration is a case in point, as its address is aimed only at its base and not at a broader constituency of 'the people'. I think Cherniavsky is absolutely right in that the hegemonic refers to a different historical moment about the relation between the market and the state. Contemporary political culture is a post-critique culture. This raises the question: what are the rhetorical strategies and forms of analysis that the present moment requires? In an era when knowledge has given way to alternative facts and post-truth - or what my friend and former colleague Purnima Bose calls the new Dark Ages - there is no easy answer to this question.

Salla: You talk about the relationship between knowledge and political action in your exchange with Tim Dean on critique in ELN. You talk about the loss of faith in the belief that knowledge is the means for knowing what to do. Do you think that what we see now is a kind of hangover from that insight? There was a belief that the knowledge produced in women's, gender and queer studies could do stuff, cause social transformation. Is what we are now witnessing not only a crisis of legitimacy but a theoretical and methodological crisis that is bound up with how to understand the relationship between knowledge and (political) action?

Robyn: Critique in these fields has always banked politically on the idea that no matter how sophisticated we might become theoretically, raising people's consciousnesses through knowledge, and giving people who have the epistemic position of subordinated knowledges legitimacy, were the true keys to social transformation. You're right, I think, to suggest that we are struggling with the consequences of a kind of lost faith in this belief or at the very least with the recognition that the right has engineered a project to 'raise' consciousnesses on its behalf and to situate different bodies and interests in the frame of subordination (think white injury). In the post-truth era, 'knowledge' is whatever your favourite news outlet or blog or social media tells you. If the present is post-critique in terms of political culture, it is not post-suspicious reading. On the contrary, conspiracy is everywhere. You can talk until you are blue in the face about the facts of climate change, for instance, and people will still say 'there's no global warming; it's all fake news'. 
Salla: What do you think the debates around critique might be symptomatic of, especially in terms of how the cultural relationship to knowledge has transformed?

Robyn: I don't really have an answer to this question as I'm not sure that what we are witnessing is a symptom in the usual sense of the word. Many of the debates seem to be precisely about what critics say they are contesting - though critics are not always contesting the same things, which is what I was pointing to earlier in differentiating between the projects of Felski and Sedgwick, or more broadly between Felski's notion of post critique and Chernivasky's. There are lots of things going on for those who have an optimistic investment in the designation 'post-critique', but one is surely about the desire to restore something of the centrality of literature. I tend to think of this restoration as being about an affective relationship to the object, one that arises in part because of the way that the technologies of everyday life have abandoned older practices of reading that were cultivated in relation to the literary object. The historical shift from print to digital culture seems bound up in calls for slow reading, descriptive reading, and a return to close reading.

Salla: But are those questions of critique? I am thinking about the desire to be able to say something about a text beyond the frameworks that have been defined as critique. I guess my question is: are aesthetic experiences or judgments about objects always political? Or is it our epistemic habit to assume that we need to foreground the politics of our readings, our analyses, claims and so on?

Robyn: In the book mentioned earlier, in a chapter on literature and popular culture, Cherniavsky makes this interesting argument that popular culture is a resource for diagnosing the conditions of the political present. She does this in much more interesting ways than we usually find in critical theory and cultural studies as she actually has an argument for why she wants to look at these kind of texts and what they can do that academic modes of analysis and critique cannot. One piece of it is about the temporality of the present. For her, popular culture has been grappling with what she calls the 'derealization' of politics for a long time, while left academic criticism has been tied to critique, which is fundamentally a realist project - we reveal the illusion in order to destroy the power that feeds off it. But in that quest for demystification, critics are all-too prone to finding objects of study that are dumber than we are. For Chernivasky, popular culture offers some smart texts that have been dealing with the transformed conditions of the political field, texts as disparate as 'Battlestar Galactica', White Boy Shuffle, and the discourses of the Occupy Movement. In her hands, the aesthetic and the political are linked in some counterintuitive ways, especially since popular culture has often been considered most in need of ideological critique.

Salla: This reminds me of the emphasis on description as a means for achieving a different kind of critique, something I find interesting...

Robyn: Yes, I think here of Heather Love's most recent work. She turns to description through the social sciences in order to make a larger argument about the problem of method or more precisely anti-methodological thinking in queer theory. I think that her arguments, like when she reads Samuel Delaney and applauds his deft ability to describe the complex and often contradictory terrain of everyday life, present an important challenge to queer theory, especially when its political investments predetermine the shape and scope of its interest in particular objects.

Queer theory's critique of gay marriage is a case in point. Queer theory tends to read participation in the marriage movement univocally, as a complicitious desire for normativity. Here desire has none of the complexity that it otherwise carries in queer theoretical inquiry, and I would venture to say that the critique of gay marriage has actually circumscribed scholarly investigations that might illuminate the diversity of reasons that move people toward marriage - economics and immigration status being two big ones, as Eithne Luibheid has discussed. Description is an interesting starting point for considering what people desire, including the way radical imaginaries do and don't align with political projects and institutions. Maggie Nelson does a good job of making these issues palpable to queer theoretical audiences in her memoir The Argonauts.

Salla: Do you have your own epistemic habit?

Robyn: I don't know what that means. (Laughs) Tell me...

Salla: This might be a difficult question to ask someone who has such an analytical mind for questioning the question, and constantly making visible your own epistemic habits - would that be a description of your epistemic habit? 
Robyn: Yes, I suppose so. My habit is to understand my habit - and everybody else's too! And especially when our habits become routine and deeply routinised, even as I recognise that people get a lot of pleasure from routine.

Salla: Could you talk a little bit about the psychoanalytic dimensions to critique and your own relationship to your objects? And maybe say something about the value of psychoanalysis as criticism and the value of being able to think about your own practice through psychoanalysis as also a form of cultural critique?

Robyn: Object Lessons was written out of a need to say that our relationship to our objects, in the fields that I care the most about, is not innocent - or more acutely, that fields that understand themselves as having not only a political impulse but a political rationale and obligation can never have innocent relations to their objects of study. There are multiple aspects of these claims and it was largely through a psychoanalytic idiom that I worked to explore them. My point was not so much to launch a critique but to offer a diagnosis, one that was not intended to demand or offer a cure. How do you cure desire? Psychoanalysis is brilliant at teaching us how we use objects for our own ends and it on this score that I side with the work on the critique of critique that wants to question the critic's sovereignty. My own work is implicated in these problems: I was trained in the tradition of critique and I see in my early publications the impulse to destroy my object of study in order to show what it didn't know about itself. So, good for me - now I can see what my object of study does and doesn't know. The paradox of course is that I actually need its failure in order to produce the positivity for my own thought.

Salla: There is a strong emphasis on and critique of a politics of exclusion in both gender/queer studies and in political activist work. We can see this kind of critique as a desire for inclusion and recognition, and as a way of undoing oppression. These critiques (against the category of woman, for example) have become routinised gestures, so the question is: does critique lose its political edge when it is predictable as a habit?

Robyn: If one of the suppositions about critique is that it operates by jolting people into a new relationship to power, knowledge, everyday life, or what have you, the risk of repetition is a kind of political numbing even as the habitual force of specific contentions works to solidify alliances between those who already believe. Solidarity on one side; deafness on the other. That's the conundrum in a political field that bends toward political struggle as shared belief. When it comes to academic critique, the risk is similar; repetition solidifies the political imaginaries of fields; people belong to fields based on their ability to cite the governing narrative, which includes the prevailing contestations to previously governing narratives. Intersectionality comes to mind here. It emerged as a critique of the disavowed universalism that is at the heart of a lot of claims to the political in feminist work. Today it is established critical doctrine and much of the discussion of its ongoing utility is over whether its critique has been muted, appropriated, etc. The more its value is repeated, the more worry there is that it has lost its critical edge. In my chapter on intersectionality in Object Lessons, I tried to grapple with the political desire of intersectional claims, how the necessary demand for a comprehensive account of the structures of power within which subjects are constructed was not without universal commitments. A desire for a map without exclusion, hence a project of universal inclusion. So far this part of the book's argument has not been taken up.

Salla: It's interesting because that is exactly what Toril Moi says about intersectionality too in her new book The Revolution of the Ordinary (2017). Critiquing this vision of wholeness internal to the debates around the concept.

Robyn: I'm not against universalising imperatives. I'd just want to lean much more heavily on the implications of universal inclusion through particularity. But the larger issue here might be about the implicit search for a practice or perspective that will do no harm, that entails no violence. I was actually talking to my undergraduate class about this today, about the desire to do no harm. I have a colleague, Wahnemma Lubiano, who talks eloquently about people's desire to be heroic political subjects. This is the subject that always does right under all conditions and can never conceive of itself as doing wrong. It certainly can't countenance the fact that to get what one wants means extinguishing - to use Elisabeth Povinelli's terms - the life that somebody else has or wants. There is work now that is really trying to grapple with this. But such grappling is at odds with a political scene finetuned to calling out complicities. I'm reminded increasingly of the attack mode of the lesbian feminist 1970s where everything from the rigor of your Marxist analysis to your shaving habits was taken as a sign of your political commitments - or their violation. Students have talked to me in office hours about their fear that they might get kicked out of their social and political groups if they are considered insufficiently queer. The historical repetition is unnerving.

Salla: This is how political actions and critique are entangled in a complicated way? 
Robyn: People want to make good political decisions, to engender the worlds we struggle to imagine. That is the aim of political action and the intense need it speaks to that the future one wants becomes a reality here and now. I understand that, but I agree with Wahneema that politics means getting dirty. Politics, not in the abstract, not as a theoretical issue, is about often about how you weigh one bad choice against another. Rarely are the available choices coherent with what you really want. In queer studies there is so much angst about the tension between the utopic future and the political negotiations that attend survival in the scene of the present. But people have to negotiate, that's where everyday life lives. It's that negotiation that most interests me - between fidelity to our political aspirations and the politics entailed in the space of ordinary life.

Salla: I attended a panel on the pedagogy of trans studies here at Duke a few days ago, where one of the main arguments was that trans should be analytically approached just like any other concept of gender. Joan Scott's work on experience, Butler's work on gender and Foucault on historicity and genealogy were referenced as the basis for this analytical framework. A question was raised about the pedagogical implications of this, as students come to gender and trans studies classes because of their identities and political commitments only to find them taken apart. This tension between being engaged in a politics around identity that is deconstructed in the name of critique, reminds me of the problematic of the personal and the theoretical - what happens when personal identity and experience are grinded through such deconstructive machinery?

Robyn: It's the pedagogical balance we have to perform in gender studies, isn't it? To cultivate and respect the kind of personal political investments that brings students to the space of the classroom while also pushing for a critical engagement with the complexity of identity, identity politics, and political identifications. I remember when feminist studies first took up theory in the 1980s, we were out of our minds with suspicioun of its allure. What was this if not an appropriation of a set of embodied experiences into an elite knowledge form? This question has never gone away.

Salla: There can also be a liberating experience in anti-identitarian work - queer theory offers that.

Robyn: For sure. Butler putting "I" in quotation marks, going to Yale to "be" a lesbian: she performs the inescapable utility of grammatical personhood and identity while undermining it. That was the big poststructuralist lesson. But we've always wanted it both ways, to deploy identity as a form of experiential truth and to protest identity's carceral logics. It's the double-bind that is fascinating and for queer theory it is evinced in some of the most widely regarded foundational work. Butler's project was to put the sovereignty of the subject and of subject identities under erasure but always from the position of authority that her own identities granted. Sedgwick was never anti-identitarian in this way. She couldn't be. Hers was always a claim for cross identifications, and it was vehemently resisted by many people for a long time.

Salla: One routinised gesture that I am interested in concerns the question of complicity that comes up in writing about others as if the writing in itself performs a kind of violence. Is there critique without the charge of complicity?

Robyn: Well, I want to say there can be. But we don't have a conception of historical change that can be articulated without a moral subject and that's a very big problem for left criticism and politics. I am very attracted to Foucault because of the way he mutes the significance of the human in his historical arc; it's the thing that people are often most angry about, but it offers some respite from the fantasy of the individual agent whose noncomplicity is somehow possible. While there are certainly degrees of complicity, the idea of the non-complicit subject is ultimately apolitical. I worked with a student at Duke, Sophie Smith, who wrote a fantastic dissertation about life on the border in Arizona. One of the things that fascinated her was the political lay of the land in which homesteaders, no matter their political affiliations, would create gates so that people could pass through their property or provide access to water wells not because they necessarily had a humanitarian interest, but because they didn't want to find dead bodies on their land. But what they did saved lives. One of her chapters traced the way people's different interests, unassimilable into any single political project or position, nonetheless contributed to left political change. This is very compelling. Things get done, not because people have a shared political vision, but because people's different interests have converged productively in relationship to a specific political situation. I don't think that the left would even know how to help orchestrate such a scenario and it is hard to imagine academic left criticism suspending ideals of community and shared political belief given how strongly these work to consolidate disciplinary practices and identities. 
Salla: I think that is an excellent example - and becomes a question of how critical fields theorise power and understand that.

Robyn: Yes, and how we think about politics and historical change.

Salla: This example reminds me of different understandings of power and the political in contemporary critique as routinised gestures - do you want to say something about that?

Robyn: As I say in Object Lessons, I'm less interested in political imaginaries than I am in the imaginary of the political. That move right there might be my epistemic habit. It's the 'wait a minute' moment, let's actually consider what constitutes politics. What do we lose when we assume its meaning is self-evident? When does the category of the political emerge historically as a foundational feature of social life? Along these lines, I'm fascinated by the history of the idea of revolution and the way it is used on the left and the right today. It's a distinctly modern concept and especially paradoxical as the figure of a political imaginary to undo the various deceptions about democracy, rationality, and the human at the heart of modernity.

Salla: The complicated relationship to the political and critique reminds me of your piece: The times we're in: Queer feminist criticism and the reparative 'turn', in which you write, I think beautifully, about the existential and moral difficulties in relationship to your mother who suffered from bipolar. You argue that critique, much like other hermeneutic frameworks, can't respond to those kinds of difficulties.

Robyn: The argument of the piece and its rhetorical strategy sought to mobilise the affective relation to my mother to demonstrate the incapacity of the epistemological, which is the core of critique, as our go-to strategy for political struggle. How do you convince someone that their reality is a fantasy or that what they fear is not real? What does it mean, in the face of such a condition as bipolar, to make the same pedagogical move over and over that seeks to teach the subject about the condition of her condition? It took me years, but I finally started to see that the kind of mental maneuvers that sustained me - that saved me really - were of no use for my mother. Critique was never a cure; knowledge did not set her free.

Today we are living, in the US at least, in a political culture that reminds me of my childhood. The landscape is without clear emotional signposts; little epistemological intervention sticks; every day bring a new whiplash. This is the affective consequence of the derealisation that Cherniavsky talks about and no doubt why her latest project is about mania. As you can see, it is this trajectory of the conversation about post-critique that most engages me, even as we do need to be closer and slower readers and to describe the complexity of the issues that face us without thinking we know in advance how to wring political judgments from them.

Fortunately there are a lot of people who are practising these kinds of self-critical reflections, not as a way to generate more critique or to fashion criticism as political transgression but as a way to live in, if not also with, the distinctly awful conditions of our present. For now, this is about as optimistic as I can get.

\section{REFERENCES}

Dean, T. and Wiegman, R. (2013). What Does Critique Want? A Critical Exchange, English Language Notes, 51(2), pp. 107-122.

Cherniavsky, E. (2017). Neocitizenship: Political Culture after Democracy. New York: New York University Press.

Felski, R. (2015). The Limits of Critique. Chicago: The University of Chicago Press.

Love, H. (2015). Doing Being Deviant: Deviance Studies, Description, and the Queer Ordinary. Differences, 26(1), pp. $74-95$.

Moi, T. (2017). The Revolution of the Ordinary. Chicago: The University of Chicago Press.

Nelson, M. (2015). The Agronauts. London: Greywolf Press.

Povinelli, E.A. (2014). On Suicide, and Other Forms of Social Extinguishment. In: J. Potts and D. Stout, eds., Theory Aside (pp. 78-97). Durham: Duke University Press.

Rooney, E. (2010). Live Free or Describe: The Reading Effect and the Persistence of Form. Differences, (21)3, pp. 112-139.

Sedgwick, E.K. (2003). Paranoid Reading and Reparative Reading: or, You're So Paranoid, You Probably Think This Introduction Is about You. In: E.K. Sedgwick, ed., Touching Feeling: Affect, Pedagogy, Performativity (pp. 123151). Durham: Duke University Press.

Smith, S. (2016). The Hole in the Fence: Policing, Peril, and Possibility in the US-Mexico Border Zone, 1994-Present. Dissertation, Duke University.

Wiegman, R. (2012). Object Lessons. Durham: Duke University Press. 
Wiegman, R. (2014). The times we're in: Feminist criticism and the reparative 'turn'. Feminist Theory, (15)1, pp. 423.

Weed, E. (2012). The Way We Read Now. History of the Present, (2)1, pp. 95-106.

\section{FURTHER READING}

Anker, E. and Felski, R. (2017). Introduction. In: E. Anker and R. Felski, eds., Critique and Postrritique (pp. 1-28). Durham: Duke University Press.

Best, S. and Marcus, S. (eds) (2009). Representations, (108)1, Fall 2009.

Chew, D. (2015). We Have Never Been Critical. We, Reading, Now. Colloquy curated by Dalglish Chew and Julie Orlemanski. Arcade. Available at: http://arcade.stanford.edu/content/we-have-never-been-critical (Accessed 20 August 2017).

Di, L. and Jeffrey, R. (2014). Criticism after Critique Aesthetics, Literature, and the Political. New York: Palgrave Macmillan.

Wilson, E. (2015). Gut Feminism. Durham: Duke University Press.

Citation: Wiegman, R. and Peltonen, S. (2017). Investigating Desires, Political Projects and Epistemic Habits in Academic Feminism: A Conversation with Robyn Wiegman. Feminist Encounters: A Journal of Critical Studies in Culture and Politics, 1(1), 11. https://doi.org/10.20897/femenc.201711

Copyright (C) 2017 by Author/s and Licensed by Lectito BV, Netherlands. This is an open access article distributed under the Creative Commons Attribution License which permits unrestricted use, distribution, and reproduction in any medium, provided the original work is properly cited. 